\title{
Why does working memory span predict complex cognition? Testing the strategy affordance hypothesis
}

\author{
HeATHER BAILEY ANd JoHn DUNLOSKY \\ Kent State University, Kent, Ohio \\ AND \\ Michael J. KANE \\ University of North Carolina, Greensboro, North Carolina
}

\begin{abstract}
We introduce and empirically evaluate the strategy affordance hypothesis, which holds that individual differences in strategy use will mediate the relationship between performances on a working memory (WM) span task and another cognitive task only when the same strategies are afforded by both tasks. One hundred fortyeight participants completed basic memory tasks and verbal span tasks that afford the same strategies, such as imagery and sentence generation, and completed reading comprehension tasks that afford different ones, such as self-questioning and summarization. Effective strategy use on WM span tasks accounted for variance in the span-memory relationship, but not for the span-comprehension relationship, supporting the strategy affordance hypothesis. Strategy use mediated the span-cognition relationship only when both tasks afforded the same strategies.
\end{abstract}

Widespread interest in working memory (WM) span tasks is driven largely by their success in predicting other cognitive abilities, such as reasoning, memory, and comprehension (e.g., Ackerman, Beier, \& Boyle, 2005; Kane, Hambrick, \& Conway, 2005). These span-cognition correlations presumably arise because span tasks measure a domain-general construct, which, in turn, is partly responsible for performance on a variety of cognitive tasks. Span tasks may tap executive attention (Engle \& Kane, 2004), mental binding (Oberauer, 2005), processing speed (Salthouse, 1991), attentional inhibition (Hasher, Lustig, \& Zacks, 2007), or other processes (for a review, see Conway, Jarrold, Kane, Miyake, \& Towse, 2007), which may contribute to performance on memory, reasoning, comprehension, and other tasks. Recently, researchers have explored (1) the degree to which variation in strategy use predicts individual differences in span performance and (2) the degree to which variation in strategy use may account for span-cognition relationships. Concerning the former issue, individual differences in strategy use do account for significant variance on span performance (Dunlosky \& Kane, 2007; Engle, Cantor, \& Carullo, 1992; Friedman \& Miyake, 2004; Kaakinen \& Hyönä, 2007; McNamara \& Scott, 2001; Turley-Ames \& Whitfield, 2003). That is, span performance is higher when individuals report using normatively effective strategies (e.g., interactive imagery or sentence generation) than when they report using less effective ones (e.g., reading).
Although strategy use can influence span performance, effective strategy use does not appear to account for spancognition relationships (Dunlosky \& Kane, 2007; Engle et al., 1992; Friedman \& Miyake, 2004; Turley-Ames \& Whitfield, 2003). For example, Turley-Ames and Whitfield examined whether individual differences in strategy use mediated the relationship between performance on the operation span (OSPAN) task and the Nelson-Denny reading test. They found that the use of normatively effective strategies on the OSPAN task did not predict performance on the Nelson-Denny reading test. Such evidence is inconsistent with a general strategy mediation hypothesis (cf. McNamara \& Scott, 2001), which is that individual differences in effective strategy use entirely (or substantially) mediate the relationship between span performance and all criterion tasks.

In the present research, we evaluate another version of strategy mediation hypotheses, which predicts that strategy use on span tasks will mediate the span-cognition relationship for some tasks, but not for others. According to this strategy affordance hypothesis, strategy use will mediate span-cognition relationships only when the same strategies are afforded by both tasks. For instance, because the to-be-remembered stimuli for the OSPAN task are individual words, they afford several associative strategies, such as rehearsal, imagery, and sentence generation (Dunlosky \& Kane, 2007; Kaakinen \& Hyönä, 2007; McNamara \& Scott, 2001; Turley-Ames \& Whitfield, 2003).

J. Dunlosky, jdunlosk@kent.edu 
Individual differences in strategy use should, therefore, mediate a span-cognition relationship when the cognitive task also affords the use of these effective strategies, such as paired-associate learning (Richardson, 1998) or learning lists of words for free recall (Hertzog, McGuire, \& Lineweaver, 1998).

By contrast, the strategies afforded by the OSPAN task cannot be readily used to improve performance on many criterion tasks typically used in the field. Consider again the results from Turley-Ames and Whitfield (2003), who used the Nelson-Denny test as a measure of reading ability. In this task, participants read several passages and then answer multiple-choice questions about them. Although strategies such as self-questioning and summarization can be used on this task (Rich \& Shepherd, 1993), these strategies are not afforded by span tasks. Thus, the strategy affordance hypothesis predicts that strategy use will not mediate the relationship between performances on the span task and the Nelson-Denny test.

To date, no evidence is available that evaluates conditions in which strategies are expected to mediate spancognition relationships, because previous experiments have used criterion tasks that do not afford the associative strategies afforded by verbal span tasks. In particular, criterion tasks have measured general verbal knowledge (i.e., verbal analogies in Dunlosky \& Kane, 2007; the verbal Scholastic Aptitude Test [SAT] in Engle et al., 1992), and reading comprehension (i.e., SAT reading comprehension in Friedman $\&$ Miyake, 2004; the Nelson-Denny test in Turley-Ames $\&$ Whitfield, 2003). A major aim of the present study was to empirically evaluate the strategy affordance hypothesis by examining whether strategy use more strongly mediates span-cognition relationships when the cognitive tasks afford the same strategies than when they do not.

To evaluate the strategy affordance hypothesis, we assessed strategy production on various cognitive tasks. For span tasks, we used the OSPAN and reading span (RSPAN) tasks. Strategy production on both span tasks was measured through set-by-set strategy reports. These strategy reports consisted of a prompt asking the participants whether they had used, on a given trial, reading, repetition, sentence generation, mental imagery, meaningful grouping, or a different strategy to remember the target items. These options were chosen because prior research had indicated that people use them on verbal span tasks (Dunlosky \& Kane, 2007; Turley-Ames \& Whitfield, 2003). Strategies were categorized into normatively effective ones (imagery, sentence generation, and grouping) and less effective ones (e.g., reading and repetition), because previous research had demonstrated that memory performance is typically higher for the normatively effective strategies on episodic memory tasks (for reviews, see Hertzog et al., 1998; Richardson, 1998) and on the OSPAN task (Dunlosky \& Kane, 2007).

The validity of these set-by-set strategy reports has been established by demonstrating significantly higher performance on trials on which participants reported using normatively effective strategies than on trials on which they reported using less effective strategies for the OSPAN and RSPAN tasks (e.g., Bailey, Dunlosky, \& Hertzog, in press;
Dunlosky \& Kane, 2007). Making these strategy reports appears to have minimal reactive effects on task performance and on strategy use (Dunlosky \& Kane, 2007), partly because people use these strategies even when they are not required to report strategies while performing these tasks (McNamara \& Scott, 2001). Moreover, Dunlosky and Kane used both concurrent (completed immediately after recall of each set) and retrospective (completed after all sets had been completed) set-by-set strategy reports. They found high consistency between both types of reports, suggesting minimal forgetting of the strategies that were used during the OSPAN task when they were reported after the task was completed. Because the reports yield similar results, we collected only retrospective strategy reports.

For the criterion tasks, we selected free-recall and paired-associate recall tasks, because they afford the same effective strategies as those afforded by these span tasks (e.g., Hertzog et al., 1998; Richardson, 1998). On the freerecall task, effective strategy production was measured through global strategy reports, in which participants described any strategy that they used to remember the words. Strategy production was assessed on the paired-associate recall task via retrospective item-by-item reports. We also selected the Nelson-Denny test and SAT practice questions, because they are commonly used criterion tasks that afford different strategies than do verbal span tasks (Rich \& Shepherd, 1993). Strategy production on both reading comprehension tasks was measured through global strategy reports, in which participants explained any strategies that they used to complete the tasks.

The strategy affordance hypothesis predicts that individual differences in the proportion of normatively effective strategy use will mediate (or partially mediate) the correlation between span and memory tasks, but not between span and reading comprehension tasks.

\section{METHOD}

\section{Participants}

A total of 148 undergraduates (86 women) from introductory psychology courses at Kent State University participated to complete a course requirement. Their mean age was 19.3 years.

\section{Materials}

OSPAN task. We used the version of the OSPAN task described in Kane et al. (2004). The participants saw a mathematical operation and a to-be-remembered word (e.g., "Is $(3 \times 2)+5=10$ ? phone"). They read the equation aloud, reported whether it was correct, and then read the word aloud. Immediately thereafter, the next operationword pair appeared on-screen. A recall cue followed the final pair of the trial, and the participants wrote the target words in serial order. The OSPAN task consisted of 15 experimenter-paced trials that included from three to seven operation-word pairs. The order of set sizes was initially randomized, and that order was used for all the participants. Following the final trial, the participants completed retrospective set-by-set strategy reports created by Dunlosky and Kane (2007). The stimuli from each trial were re-presented together on-screen (including all of the equations and words), and the participants indicated which strategy they had used to remember the words on that particular trial.

RSPAN task. We used a modified version of the RSPAN task from Kane et al. (2004). The participants saw either a logical or a 
nonsensical sentence and an unrelated word (e.g., "Mr. Owens left the lawnmower in the lemon.? eagle"). The participants read the sentence aloud, reported whether it made sense, and then read the word aloud. Once the word had been read aloud, the next sentence-word pair appeared on-screen. After the final pair of each trial, a recall cue prompted the participants to write the target words in serial order. The RSPAN task consisted of 15 experimenter-paced trials that included from three to seven sentence-word pairs presented in random order. The same set-by-set strategy reports as those from the OSPAN task were administered after the final trial of the RSPAN task. Performance on both span tasks was computed using partial-credit unit scoring (see Conway et al., 2005).

Paired-associates cued-recall task. The participants studied 40 unrelated word pairs (e.g., DOCTOR-LOBSTER) presented on the computer screen at a 5-sec rate. During the recall phase, the cues (e.g., DOCTOR) were presented in the same order as during encoding, and the participants typed in the correct response (e.g., LOBSTER). Following the final recall trial, the participants completed a strategy report in which they recounted which specific strategy (passive reading, rote repetition, interactive imagery, sentence generation, or "other") they had used to remember each word pair (re-presented on-screen).

Free recall. A list of 20 words appeared individually on-screen at a 5 -sec rate. The participants immediately recalled the words in any order. After recall, the participants described the strategies that they had used to help them remember the words, and they could indicate having used more than one strategy. We computed the percentage of participants who reported any given strategy.

Nelson-Denny reading comprehension test. The participants read eight passages and answered multiple-choice questions after each, with a 12-min time limit. Scores reflected the proportion of correctly answered items. After they had completed the NelsonDenny test, the participants completed a global strategy report in which they described any strategy that they had used to help them complete the task. The percentage of participants who reported any given strategy was computed.

Scholastic Aptitude Test practice questions. The participants read eight expository passages and answered eight questions about each, with a 15-min time limit (from Rawson \& Dunlosky, 2002). Scores reflected the proportions of correctly answered items. After finishing this task, the participants completed a global strategy report in which they described any strategy that they had used to help them complete the task. The percentage of participants who reported any given strategy was computed.

\section{Procedure}

The participants completed two 1-h sessions, separated by 1 week. Each session consisted of one WM span task, one reading comprehension task, and one memory task, with the tasks administered on a Dell Optiplex GX280 computer. In Session 1, the participants completed the OSPAN task, the Nelson-Denny test, and the pairedassociates task. In Session 2, they completed the RSPAN task, SAT practice questions, and then the free-recall task.

\section{RESULTS}

Before we present the mediation analyses most relevant to the strategy affordance hypothesis, we will present (1) self-reported strategy use in order to establish that the participants employed normatively effective strategies while performing the span tasks and (2) span performance as a function of strategy use in order to validate that effective strategies improved span performance. These analyses replicate Dunlosky and Kane (2007), who investigated only the OSPAN task, but importantly, they also extend the results to the RSPAN task.

\section{Proportion of Reported Strategy Use}

For any given task, few participants reported using every strategy. To increase the power of analyses, we divided responses on the strategy reports into two categories: normatively effective and normatively less effective. Given outcomes from prior research (e.g., Richardson, 1998), we considered interactive imagery, sentence generation, and grouping to be normatively effective and passive reading and rote repetition to be normatively less effective (the "other" option was not classifiable as effective or ineffective).

Table 1 presents the means across individual participants' proportions of span task trials on which a given strategy was reported. Even though span tasks are designed to minimize strategy use, effective strategies were reported on an average of $28 \%$ and $26 \%$ of the OSPAN and RSPAN trials, respectively. Table 1 also includes the proportion of reported strategy use for the pairedassociate and free-recall tasks. As in previous research, we present means across individual participants' proportions of trials on which a given strategy was reported in the paired-associate task (Dunlosky \& Hertzog, 1998) and the proportion of participants who reported using each strategy in the free-recall task (Hertzog et al., 1998). The participants reported using interactive imagery and sentence generation for both memory tasks, demonstrating that participants use similar effective strategies on the span tasks and these memory tasks.

By contrast, as compared with the span and memory tasks, the participants reported using different strategies when performing the comprehension tests. For the Nelson-Denny test and SAT questions, respectively, 27\% and $36 \%$ of the participants reported skimming, $35 \%$ and

Table 1

Proportions of Reported Strategy Use for a Given Strategy $(N=148)$

\begin{tabular}{|c|c|c|c|c|c|c|c|c|c|c|c|c|}
\hline \multirow[b]{3}{*}{ Task } & \multicolumn{12}{|c|}{ Strategy } \\
\hline & \multicolumn{2}{|c|}{ Read } & \multicolumn{2}{|c|}{ Repetition } & \multicolumn{2}{|c|}{ Imagery } & \multicolumn{2}{|c|}{ Sentence } & \multicolumn{2}{|c|}{ Grouping } & \multicolumn{2}{|c|}{ Other } \\
\hline & $M$ & $S E$ & $M$ & $\overline{S E}$ & $M$ & $S E$ & $M$ & $S E$ & $M$ & $S E$ & $M$ & $S E$ \\
\hline Operation span ${ }^{\mathrm{a}}$ & .32 & .03 & .34 & .03 & .11 & .01 & .10 & .02 & .07 & .01 & .06 & .01 \\
\hline Reading span & .35 & .04 & .34 & .03 & .08 & .01 & .11 & .02 & .07 & .01 & .05 & .02 \\
\hline Paired-associate recall & .23 & .02 & .20 & .02 & .31 & .03 & .20 & .02 & & & .06 & .01 \\
\hline Free recallb & \multicolumn{2}{|c|}{.12} & \multicolumn{2}{|c|}{.42} & \multicolumn{2}{|c|}{.22} & \multicolumn{2}{|c|}{.29} & \multicolumn{2}{|c|}{$\begin{array}{l}\mathrm{N} / \mathrm{A} \\
.19\end{array}$} & \multicolumn{2}{|c|}{.18} \\
\hline
\end{tabular}

aFor span tasks and paired-associate recall, values are means across individual participants' proportions of trials on which a given strategy was reported. bFor free recall, the values are the proportions of participants who reported a given strategy. The sum of the free-recall proportions is greater than 1.0 because participants were allowed to report using more than one strategy. 
Table 2

Proportions of Trials on Which Participants Reported Using a Given Strategy As a Function of Set Size

\begin{tabular}{|c|c|c|c|c|}
\hline \multirow[b]{3}{*}{ Set Size } & \multicolumn{4}{|c|}{ Strategy Reported } \\
\hline & \multicolumn{2}{|c|}{ Less Effective } & \multicolumn{2}{|c|}{ Effective } \\
\hline & $M$ & $S E$ & $M$ & $S E$ \\
\hline \multicolumn{5}{|c|}{ Operation Span } \\
\hline Smaller & .71 & .03 & .24 & .03 \\
\hline Larger & .65 & .03 & .29 & .03 \\
\hline \multicolumn{5}{|c|}{ Reading Span } \\
\hline Smaller & .69 & .03 & .25 & .03 \\
\hline Larger & .67 & .03 & .28 & .03 \\
\hline
\end{tabular}

Note-Less effective, reports of reading and repetition; effective, reports of imagery, sentence generation, and grouping. Smaller refers to set sizes of 3 and 4; larger refers to set sizes of 6 and 7 . Values do not sum to 1.0 within rows because reports of "other strategy" were excluded from these analyses.

$24 \%$ reported reading the questions first before reading the passage, $30 \%$ and $24 \%$ reported summarizing the main ideas, and $8 \%$ and $16 \%$ reported using no strategy (i.e., reading the passage and then answering the questions). Just as important, fewer than $1 \%$ of the participants reported using any of the strategies that were commonly used on the verbal span tasks (e.g., imagery).

It is worth noting again that previous research has indicated that set-by-set (on the OSPAN task; Dunlosky \& Kane, 2007) and item-by-item (on paired-associate recall; Dunlosky \& Hertzog, 2001) reports do not have reactive effects on strategy use. That is, the act of making strategy reports on one task does not influence strategy use on that task or on later tasks. Additional support for this claim has come from the results of previous studies, which have demonstrated similar proportions of effective strategy use, as compared with the proportions observed in the present study on the OSPAN task (present study, $M=0.28$; Dunlosky \& Kane [2007], $M=.23$ ), the RSPAN task (present study, $M=.26$; Bailey et al. [in press], $M=.27$ ), pairedassociate recall (present study, $M=.51$; Dunlosky \& Hertzog [1998], $M=.58$ ), and free recall (present study, $M=.49$; Hertzog et al. [1998], $M=.49$ ). Thus, in the present investigation, the participants' reports on one task were not likely to have had a reactive effect on reported strategy use on other tasks.

Finally, we also examined strategy use as a function of set size, either smaller (sizes 3 and 4) or larger (6 and 7). As is evident from an inspection of Table 2, the participants tended more often to report using less effective than effective strategies, for both the OSPAN task $[F(1,147)=$ 62.6, $\left.M S_{\mathrm{e}}=25.6\right]$ and the RSPAN task $[F(1,117)=46.5$, $\left.M S_{\mathrm{e}}=20.0\right]$. For both tasks, the main effect of set size was not significant $\left(F_{\mathrm{S}}<1\right)$. The interaction was not reliable for the RSPAN task $(F<3.7)$, but it was reliable for the OSPAN task $\left[F(1,147)=13.1, M S_{\mathrm{e}}=0.39\right]$, indicating that the participants reported using effective strategies slightly more often for larger set sizes.

\section{Performance As a Function of Reported Strategy Use}

For any strategy mediation hypotheses to be viable (whether general strategy mediation or strategy affordance), individual differences in effective strategy use on the span tasks must be related to performance. To evaluate this relationship, we averaged performance across trials by each kind of strategy report for each participant. Mean performance across participants' values is presented in Table 3. As was mentioned above, we compared performance averaged across trials on which the participants reported using normatively effective strategies (i.e., imagery, sentence generation, and grouping) versus performance averaged across trials on which the participants reported less effective strategies (i.e., reading and rehearsal).

On the OSPAN task, the proportion of correctly recalled items was significantly higher when individuals reported using normatively effective strategies (.64) than when they reported using normatively less effective strategies $(.54)[t(83)=4.01, p<.001$, Cohen's $(1988) d=$ $.58]$. The same pattern emerged for RSPAN $[t(59)=3.86$, $p<.001, d=.58$ (effective strategies $=.60$; ineffective strategies $=.49)] .{ }^{1}$ Note that the degrees of freedom are relatively low, because only participants who reported using at least one effective and one less effective strategy could be included in these analyses, which resulted in dropping participants who reported using only effective ones (OSPAN, $n=59$; RSPAN, $n=48$ ) and those who reported using only less effective ones (OSPAN, $n=4$; RSPAN, $n=5$ ). For those included in the analyses, strategy use predicted span performance, as was expected (Dunlosky \& Kane, 2007).

Although less relevant to evaluating the strategy affordance hypothesis, we also examined whether effective strategy use was related to performance on the memory tasks. For paired-associate recall, the participants recalled $66 \%$ of the word pairs when they reported using effective strategies and only $17 \%$ when they reported using less effective strategies $[t(98)=15.6, p<.001, d=1.88]$. The same pattern was found for free recall: The participants who reported using any effective strategies recalled 53\% of the words, versus $34 \%$ of the words for the participants who reported using only normatively less effective strategies $[t(116)=5.83, p<.001, d=1.11]$.

Table 3

Performance As a Function of Reported Strategy Use by Task

\begin{tabular}{|c|c|c|c|c|c|c|c|c|c|c|c|c|}
\hline \multirow[b]{2}{*}{ Task } & \multicolumn{2}{|c|}{ Read } & \multicolumn{2}{|c|}{ Repetition } & \multicolumn{2}{|c|}{ Imagery } & \multicolumn{2}{|c|}{ Sentence } & \multicolumn{2}{|c|}{ Grouping } & \multicolumn{2}{|c|}{ Other } \\
\hline & $M$ & $S E$ & $M$ & $S E$ & $M$ & $S E$ & $M$ & $S E$ & $M$ & $S E$ & $M$ & $S E$ \\
\hline Operation span & .48 & .02 & .56 & .02 & .66 & .03 & .55 & .03 & .65 & .03 & .47 & .03 \\
\hline Reading span & .46 & .02 & .53 & .02 & .62 & .04 & .61 & .03 & .61 & .04 & .37 & .05 \\
\hline Paired-associate recall & .03 & .01 & .34 & .04 & .65 & .03 & .62 & .04 & \multicolumn{2}{|c|}{$\mathrm{N} / \mathrm{A}$} & .49 & .06 \\
\hline
\end{tabular}


Table 4

Zero-Order Correlations for All Tasks

\begin{tabular}{lccccc}
\hline \multicolumn{1}{c}{ Task } & 1 & 2 & 3 & 4 & 5 \\
\hline 1. Operation span & & & & & \\
2. Reading span & $.67^{* *}$ & & & & \\
3. SAT questions & $.25^{* *}$ & $.41^{* *}$ & & & \\
4. Nelson-Denny & $.21^{* *}$ & $.32^{* *}$ & $.52^{* *}$ & & \\
5. Paired-association recall & $.31^{* *}$ & $.32^{* *}$ & $.26^{* *}$ & $.20^{* *}$ & \\
6. Free recall & $.45^{* *}$ & $.53^{* *}$ & $.41^{* *}$ & $.27^{* *}$ & $.46^{* *}$ \\
\hline
\end{tabular}
${ }^{* *} p<.01$.

Table 5

Correlations for Composite Variables

\begin{tabular}{llll}
\hline \multicolumn{1}{c}{ Composite Variable } & 1 & 2 & 3 \\
\hline 1. Working memory span & & & \\
2. Memory & $.44^{* *}$ & & \\
3. Comprehension & $.38^{* *}$ & $.32^{* *}$ & \\
4. Effective strategy use (span) & $.28^{* *}$ & $.38^{* *}$ & .11 \\
\hline
\end{tabular}

Note-Effective strategy use is the proportion of normatively effective strategies that participants reported using on the operation span and reading span tasks. See the text for details. ${ }^{* *} p<.01$.

\section{Strategy Use As a Mediator}

To evaluate the strategy affordance hypothesis, we first examined the zero-order correlations between the span and the criterion tasks (Table 4). The two tasks that measured each construct (span, episodic memory, and comprehension) were significantly related to one another (span task, $r=.67$; memory task, $r=.46$; comprehension task, $r=.52$ ). Thus, we used composite variables in conducting the mediational analyses, computed by averaging the standardized scores ( $z$ scores) on each task. Consistent with previous research, the WM span composite was significantly correlated with both the memory and the comprehension composites (Table 5), and the magnitude of these correlations did not differ statistically $[t(145)<1]$. Note that strategy use on the span tasks was significantly related to performance on the memory tasks, suggesting that strategy use may partly explain why span predicts performance on cognitive tasks. By contrast, effective strat-

Table 6

Summary of Hierarchical Regression Analyses for Variables Predicting Criterion Task Performance (Using Composite Variables)

\begin{tabular}{|c|c|c|c|}
\hline Variable & $R^{2}$ & $\beta$ & $F$ \\
\hline \multicolumn{4}{|c|}{ Memory Composite } \\
\hline \multicolumn{4}{|l|}{ Step 1} \\
\hline Span performance & .20 & $.44^{* * *}$ & 35.58 \\
\hline Step 2 & .27 & & \\
\hline Effective strategy use & .15 & $.38^{* * *}$ & 25.11 \\
\hline Span performance & .12 & $.38^{* * *}$ & 26.73 \\
\hline \multicolumn{4}{|c|}{ Comprehension Composite } \\
\hline \multicolumn{4}{|l|}{ Step 1} \\
\hline Span performance & .14 & $.37^{* * *}$ & 23.98 \\
\hline Step 2 & .14 & & \\
\hline Effective strategy use & .01 & .11 & 1.88 \\
\hline Span performance & .13 & $.37^{* * * *}$ & 11.91 \\
\hline
\end{tabular}

Note-Effective strategy use is the proportion of normatively effective strategies that participants reported using on each task. $R^{2}$ listed beside "Step 2" is the total amount of variance in criterion task performance accounted for by effective strategy use and span performance. ${ }^{* * *} p<$ .001 . egy use on the span tasks was not significantly related to performance on the comprehension tasks, which is inconsistent with a general strategy mediation hypothesis but indirectly supports the strategy affordance hypothesis.

Most important, hierarchical regressions were conducted separately on the memory composite and on the comprehension composite, using span and effective strategy use as predictors. On Step 1 of the regression analyses, span performance was entered as a predictor of a given composite. On Step 2, proportion of effective strategy use was entered first, followed by span performance. These analyses allowed us to compare the amount of variance $\left(R^{2}\right)$ in criterion task performance accounted for by span performance before (Step 1) and after (Step 2) controlling for strategy use. According to the strategy affordance hypothesis, span performance will account for less variance only in the memory composite after controlling for strategy use (Step 2) than it will when entered alone (Step 1). Results of these analyses are presented in Table 6.

Concerning the span-memory relationship, the results from Step 1 of the regression showed that $20 \%$ of the variance in memory performance was shared with span performance. After controlling for strategy use (Step 2), memory performance shared only $12 \%$ of its variance with span performance. This reduction in shared variance indicates that strategy use accounts for $40 \%$ of the spanrelated variance in memory performance - that is, $(20-$ 12) $/ 20] * 100=40 \%$. By contrast, the total amount of shared variance between span and comprehension performance was $14 \%$. After entering strategy use (Step 2), their shared variance was $13 \%$, indicating that strategy use accounts for only $7 \%$ of the variance in the spancomprehension relationship.

The results from these analyses support predictions from the strategy affordance hypothesis; nevertheless, an alternative explanation is that differential mediation arose because more variance is shared between the span and memory composites, as compared with the span and comprehension composites. Although a $t$ test revealed no significant differences between the two span-cognition correlations $[t(145)<1$; Steiger, 1980], we conducted another set of regressions similar to those described above, except that here, individual tasks, rather than composites, were used. This analysis was informative because, as is shown in Table 4, correlations between individual span and comprehension tasks (e.g., the RSPAN task and the NelsonDenny test) are similar in magnitude to, and sometimes even numerically greater than (e.g., RSPAN and SAT), the correlations between individual span and memory tasks (e.g., RSPAN and paired-associate recall). Outcomes from these regressions were consistent with those using composite variables: Strategy use mediated the span-memory relationships, but not the span-comprehension relationships (for detailed results, see the Appendix).

In the preceding analyses, the proportion of effective strategy use was entered into the regressions first, followed by span performance (at Step 2), to assess the amount of span-related variance in criterion task performance associated with strategy use. A related issue concerns whether strategy use has a unique contribution to criterion task 
performance beyond that due to span performance. To examine this issue, we conducted a final set of regression analyses in which span performance was entered first, followed by effective strategy use. After controlling for variance accounted for by span performance, effective strategy use significantly predicted memory performance $\left(R^{2}=.07, \beta=.28, p<.001\right)$, but not comprehension performance $\left(R^{2}=.00, \beta=.01, p>.05\right)$.

\section{DISCUSSION}

The present evidence is consistent with the strategy affordance hypothesis: Strategy use should mediate spancognition relationships when - and only when - identical strategies are afforded by span tasks and the other cognitive tasks. Our results help explain why previous studies failed to demonstrate that strategy use accounts for the relationship between span and cognitive abilities, such as general verbal knowledge and reading comprehension (Dunlosky \& Kane, 2007; Engle et al., 1992; Friedman \& Miyake, 2004; Turley-Ames \& Whitfield, 2003). An alternative explanation of this evidence is that strategy use mediated more of the span-memory relationship because, initially, span shared more variance with performance on the memory tasks than with performance on the comprehension tasks. This explanation is not viable, however, because the present results demonstrate equivalent correlations between the span-memory and the span-comprehension relationships. Of course, given the correlational nature of this investigation, some fourthand currently unknown - construct may account for the observed relationships between measures of span, strategy use, and memory performance. These results do, however, provide strong evidence against the general strategy mediation hypothesis and evidence that is clearly consistent with the strategy affordance hypothesis: Individual differences in strategy use are not responsible for all spancognition relationships - in particular, those in which the span and cognitive tasks do not afford the same strategies (e.g., span-comprehension correlations).

The present results, among others (e.g., Dunlosky \& Kane, 2007; Engle et al., 1992; Friedman \& Miyake, 2004; Turley-Ames \& Whitfield, 2003), indicate that strategy use can account for some of the performance variance in both the OSPAN and the RSPAN tasks, both of which are popular WM measures. Thus, when using these and other verbal span tasks, researchers should consider measuring strategy use, so that strategic behavior can be factored out of analyses that are relevant to investigating domain-general theories of working memory. Moreover, such results also motivate a critical question for future research - namely, to what extent does the capability to generate and implement effective strategies cause the statistical relationship between strategy use and span performance? According to the strategy-as-cause hypothesis, individuals who are more strategic merely obtain higher span scores. Alternatively, the strategy-as-effect hypothesis proposes that having higher WM capacity (WMC) allows one to be more strategic, which, in turn, contributes to span scores. Although strategy may be both cause and effect, some previous research seems to be more in accord with a strategy-as-effect hypothesis (for a brief review, see Dunlosky \& Kane, 2007). For instance, Imbo, Duverne, and Lemaire (2007) investigated the role of WMC in solving arithmetic problems, and they concluded that "when fewer working memory resources were left, participants chose the simple strategy more often, especially to solve the most demanding problems" (p. 1258). Even if enhanced WMC increases the likelihood of strategy use (as per the strategy-as-effect hypothesis), it would not necessarily rule out the strategy affordance hypothesis for explaining span-cognition relationships. In particular, even if a high-span individual has the ability to use strategies on other tasks, this individual may be more strategic for some kinds of task (e.g., those affording verbal mediators) and may be less so for others kinds. Certainly, specific evaluation of these hypotheses is necessary, and the setby-set methods described here for the span tasks should be invaluable to such pursuits.

Of importance, strategy use did not completely mediate even the span-memory relationship: Effective strategy use on the span tasks accounted for only $40 \%$ of the spanmemory relationships. Thus, although strategies may mediate span-cognition relationships under some circumstances, our findings suggest that even when the tasks afford the same strategies, other factors play a significant role in determining why span performance predicts individual differences in cognition. In addition to strategy use, constructs such as executive attention, processing speed, and attentional inhibition apparently play a role in the correlations observed between span tasks and other memory tasks; moreover, they very likely contribute to correlations among span and other cognitive tasks, such as reading comprehension, reasoning, and problem solving.

\section{AUTHOR NOTE}

Correspondence concerning this article should be addressed to J. Dunlosky, Department of Psychology, Kent State University, P. O. Box 5190, Kent, OH 44242-0001 (e-mail: jdunlosk@kent.edu).

\section{REFERENCES}

Ackerman, P. L., Beier, M. E., \& Boyle, M. O. (2005). Working memory and intelligence: The same or different constructs? Psychological Bulletin, 131, 30-60.

Bailey, H., Dunlosky, J., \& Hertzog, C. (in press). Does differential strategy use account for age-related deficits in working-memory performance? Psychology \& Aging.

CoHen, J. (1988). Statistical power analysis for the behavioral sciences (2nd ed.). Hillsdale, NJ: Erlbaum.

Conway, A. R. A., Jarrold, C., Kane, M. J., Miyake, A., \& Towse, J. N. (EDS.) (2007). Variations in working memory. Oxford: Oxford University Press.

Conway, A. R. A., Kane, M. J., Bunting, M. F., Hambrick, D. Z., Wilhelm, O., \& ENGLE, R. W. (2005). Working memory span tasks: A methodological review and user's guide. Psychonomic Bulletin \& Review, 12, 769-786.

Dunlosky, J., \& Hertzog, C. (1998). Aging and deficits in associative memory: What is the role of strategy production? Psychology \& Aging, 13, 597-607.

Dunlosky, J., \& Hertzog, C. (2001). Measuring strategy production during associative learning: The relative utility of concurrent versus retrospective reports. Memory \& Cognition, 29, 247-253. 
Dunlosky, J., \& Kane, M. J. (2007). The contributions of strategy use to working memory span: A comparison of strategy assessment methods. Quarterly Journal of Experimental Psychology, 60, 12271245 .

Engle, R. W., Cantor, J., \& Carullo, J. J. (1992). Individual differences in working memory and comprehension: A test of four hypotheses. Journal of Experimental Psychology: Learning, Memory, \& Cognition, 18, 972-992.

Engle, R. W., \& KAnE, M. J. (2004). Executive attention, working memory capacity, and a two-factor theory of cognitive control. In B. H. Ross (Ed.), The psychology of learning and motivation (Vol. 44, pp. 145-199). New York: Academic Press.

Friedman, N. P., \& Miyake, A. (2004). The reading span test and its predictive power for reading comprehension ability. Journal of Memory \& Language, 51, 136-158.

HAsher, L., Lustig, C., \& ZACKs, R. T. (2007). Inhibitory mechanisms and the control of attention. In A. R. A. Conway, C. Jarrold, M. J. Kane, A. Miyake, \& J. N. Towse (Eds.), Variation in working memory (pp. 227-249). Oxford: Oxford University Press.

Hertzog, C., McGuire, C. L., \& Lineweaver, T. T. (1998). Aging, attributions, perceived control and strategy use in a free recall task. Aging, Neuropsychology, \& Cognition, 15, 85-106.

Imbo, I., Duverne, S., \& Lemaire, P. (2007). Working memory, strategy execution, and strategy selection in mental arithmetic. Quarterly Journal of Experimental Psychology, 60, 1246-1264.

KAAKInEN, J. K., \& HyöNÄ, J. (2007). Strategy use in the reading span test: An analysis of eye movements and reported encoding strategies. Memory, 15, 634-646.

Kane, M. J., Hambrick, D. Z., \& Conway, A. R. A. (2005). Working memory capacity and fluid intelligence are strongly related constructs: Comment on Ackerman, Beier, and Boyle (2004). Psychological Bulletin, 131, 66-71.

Kane, M. J., Hambrick, D. Z., Tuholski, S. W., Wilhelm, O., Payne, T. W., \& ENGLE, R. W. (2004). The generality of working memory capacity: A latent-variable approach to verbal and visuospatial memory span and reasoning. Journal of Experimental Psychology: General, 133, 189-217.

McNamara, D. S., \& ScotT, J. L. (2001). Working memory capacity and strategy use. Memory \& Cognition, 29, 10-17.

OBERAuER, K. (2005). Binding and inhibition in working memory: Individual and age differences in short-term recognition. Journal of Experimental Psychology: General, 134, 368-387.

Rawson, K. A., \& Dunlosky, J. (2002). Are performance predictions for text based on ease of processing? Journal of Experimental Psychology: Learning, Memory, \& Cognition, 28, 69-80.

RICH, R., \& SHEPHERD, M. J. (1993). Teaching text comprehension strategies to adult poor readers. Reading \& Writing, 5, 387-402.

RICHARDSON, J. T. E. (1998). The availability and effectiveness of reported mediators in associative learning: A historical review and an experimental investigation. Psychonomic Bulletin \& Review, 5, 597-614.

Salthouse, T. A. (1991). Mediation of adult age differences in cognition by reductions in working memory and speed of processing. Psychological Science, 2, 179-183.

Steiger, J. H. (1980). Tests for comparing elements of a correlation matrix. Psychological Bulletin, 87, 245-251.

Turley-Ames, K. J., \& Whitfield, M. M. (2003). Strategy training and working memory task performance. Journal of Memory \& Language, 49, 446-468.

\section{NOTE}

1. In comparison with passive reading, rote repetition may be a more effective strategy on span tasks, because Turley-Ames and Whitfield (2003) found that OSPAN performance was higher when participants were instructed to use repetition rather than passive reading. To address this possibility, we conducted the same analyses with rote repetition included in the normatively effective strategy category. The results indicated that span performance was significantly higher when effective, rather than less effective, strategies were used, although this effect was not as strong as when rote repetition was considered normatively less effective.

\section{APPENDIX}

To supplement analyses of composite scores, we conducted hierarchical regressions on each of the individual span and criterion tasks. At Step 1 of the regression analyses, we entered either OSPAN or RSPAN performance as a predictor of a given criterion task. At Step 2, proportion of effective strategy use (for the span task under scrutiny) was first entered, followed by either OSPAN or RSPAN performance. These analyses allowed us to compare the amount of variance $\left(R^{2}\right)$ in criterion task performance accounted for by span performance before (Step 1) and after (Step 2) controlling for strategy use (see Table A1).

Table A1

Summary of Hierarchical Regression Analyses for Variables Predicting Criterion Task Performance (Using Individual Tasks)

\begin{tabular}{|c|c|c|c|c|c|c|c|c|}
\hline \multirow[b]{2}{*}{ Variable } & \multicolumn{2}{|c|}{ PA Recall } & \multicolumn{2}{|c|}{ Free Recall } & \multicolumn{2}{|c|}{$\begin{array}{c}\text { Nelson- } \\
\text { Denny }\end{array}$} & \multicolumn{2}{|c|}{ SAT } \\
\hline & $R^{2}$ & $\beta$ & $R^{2}$ & $\beta$ & $R^{2}$ & $\beta$ & $R^{2}$ & $\beta$ \\
\hline \multicolumn{9}{|l|}{ Step 1} \\
\hline OSPAN performance & .10 & $.31^{* * *}$ & .20 & $.45^{* * *}$ & .04 & $.21^{*}$ & .06 & $.25^{*}$ \\
\hline \multicolumn{9}{|l|}{ Step 2} \\
\hline Effective strategy use & .09 & $.29^{* * * *}$ & .12 & $.34^{* * *}$ & .01 & .08 & .00 & .03 \\
\hline OSPAN performance & .06 & $.25^{* *}$ & .13 & $.38^{* * *}$ & .04 & $.20^{*}$ & .07 & $.28^{*}$ \\
\hline \multicolumn{9}{|l|}{ Step 1} \\
\hline RSPAN performance & .10 & $.32^{* *}$ & .28 & $.53^{* * *}$ & .11 & $.32^{* * *}$ & .17 & $.41^{* * *}$ \\
\hline \multicolumn{9}{|l|}{ Step 2} \\
\hline Effective strategy use & .10 & $.31^{* *}$ & .19 & $.44^{* * *}$ & .00 & .04 & .01 & .11 \\
\hline RSPAN performance & .06 & $.26^{*}$ & .18 & $.44^{* * *}$ & .11 & $.34^{* * *}$ & .16 & $.41^{* * *}$ \\
\hline
\end{tabular}




\section{APPENDIX (Continued)}

Finally, the values (variance accounted for by strategy use) presented in Table A2 were calculated using the formula described in the Results section:

Variance accounted for by strategy use $=\left[\left(R^{2}\right.\right.$ in Step $1-R^{2}$ in Step 2$) / R^{2}$ in Step 1] 100.

As is evident from Table A2, effective strategy use consistently accounted for some of the span-memory relationship but accounted for minimal variance between span and comprehension performance.

Table A2

Amount of Shared Variance Between a Given Pair of Tasks Accounted for by Strategy Use

\begin{tabular}{lcccc}
\hline & $\begin{array}{c}\text { Paired-Associate } \\
\text { Recall }\end{array}$ & $\begin{array}{c}\text { Free } \\
\text { Recall }\end{array}$ & $\begin{array}{c}\text { Nelson- } \\
\text { Denny }\end{array}$ & SAT \\
\hline Operation span & $44 \%$ & $37 \%$ & $12 \%$ & $0 \%$ \\
Reading span & $35 \%$ & $37 \%$ & $0 \%$ & $7 \%$ \\
\hline
\end{tabular}

(Manuscript received April 21, 2008;

revision accepted for publication August 19, 2008.) 